\title{
Practice-based customer care
}

\author{
Having the right words can be a blessing ... or an embarrassment.
} Stephen Hancocks notes why 'your call is important to us'.

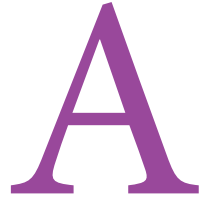

script can act as a sort of emotional safety net when you don't quite know what to say, providing of course that it is used with care. Getting the words right is something we all long to do. The 'oh I wish I'd said that' syndrome is a familiar one indeed, as is the longing of, 'if only I'd thought quickly enough I'd have loved to have said...' So having the words written down often seems like a good idea to help us get over the feared embarrassment of variously not getting it right, saying the wrong thing or, nightmare of nightmares, drying-up completely.

However, as with all good ideas they have their limitations. Witness when the last speaker of a day's conference rises sheepishly to the podium, beautifully typed presentation clutched sweatily in hand to announce that the previous speakers have already said all that she was going to say. The supposed flexibility of the scripted support becomes a ghastly straitjacket of concrete proportions.

Sadly, the same can be true of the very best intentioned practice-based customer care services. Quite apart from anything else, the script is only as good as the performer. Take for instance the cleverly crafted question for the receptionist to ask of the patient: 'how would you like to pay this morning Mrs Williams?' Clever because it only offers Mrs Williams the option to pay in different ways, as distinct from the question: 'would you like to pay today?' which naturally invites the response 'no'.

Now it is perfectly reasonably to suggest reading such a question if the new receptionist is a little hesitant about getting it right. Unfortunately, it takes the skill of an autocue-familiar newsreader to think quickly enough to adapt it. So, when at three o'clock in the afternoon Suzy on reception smiles pleasantly at Major Clive Witherington-Fortesque and says in rather stilted English, 'how would you like to pay this morning Mrs Williams?' there is a nasty pause while the bemused military gentleman abruptly replies, 'Visa, before the sound of rustling pages is followed by the numbing, 'or would you rather pay by credit card Audrey?'

Similarly insensitive occurrences can easily happen with the telephone. Answer machines are of course a great convenience but have you listened to your own recently? Does it have the slightly unnerving sound of an ambulance

\section{${ }^{` A}$ nswer machines are \\ a great convenience}

but have you listened

to your own recently?

Does it have the

\section{unnerving sound of an \\ ambulance going past}

in the background?'

going past in the background for instance? Very reassuring to the new patient. Worse still are the neatly scripted messages that get out of sync. Calling at $4.20 \mathrm{pm}$ to be told that the practice is closed for lunch can undeniably send the wrong signals about your customer awareness arrangements.

The there are the increasingly common; 'if ... then press' scripted niceties. They are designed to help and guide

but performer beware.

'Thank you for call-

ing Share and Care Dental

Practice. If

you are a

new patient please press 1 , if you are an existing patient who wants to make an appointment please press 2. If you are an existing patient who wants to change an appointment but doesn't want Tuesdays please press 3 , if you are calling in pain please use your number keys to enter the FDI notation code for the tooth that is giving you trouble...' and so on.

Perhaps most infuriating of all though are those dreadfully contrived telephone queuing messages. 'Your call is important to us here at Slick Dental Centre. You are currently held in a queue as all of our appointment scheduling operatives are busy but please hold and we will process your timetabling requirements as soon as possible.' You hold. You hold some more.

Then the music that has that same bland, narrowly escaped death quality of the 'just landed and taxiing around Gatwick airport for the sixth time' kind is interrupted by 'Your call is important to us...' Surprise, a real human voice interjects but you're not out of the woods yet because the opening gambit takes another halfcentury. 'Sorry to have kept you waiting, this is Slick Dental Centre, Mandy speaking, how may I be of service to you today?'

'I wanted to make an appointment for a check-up please.'

'How would you like to pay this morning Mrs Williams?'

'What?'

'Ooo, sorry. Visa would do nicely ... oh, I've turned over two pages. Hang on, can I put you back on hold?

'Your call is important to us...' Grrrrrrr.

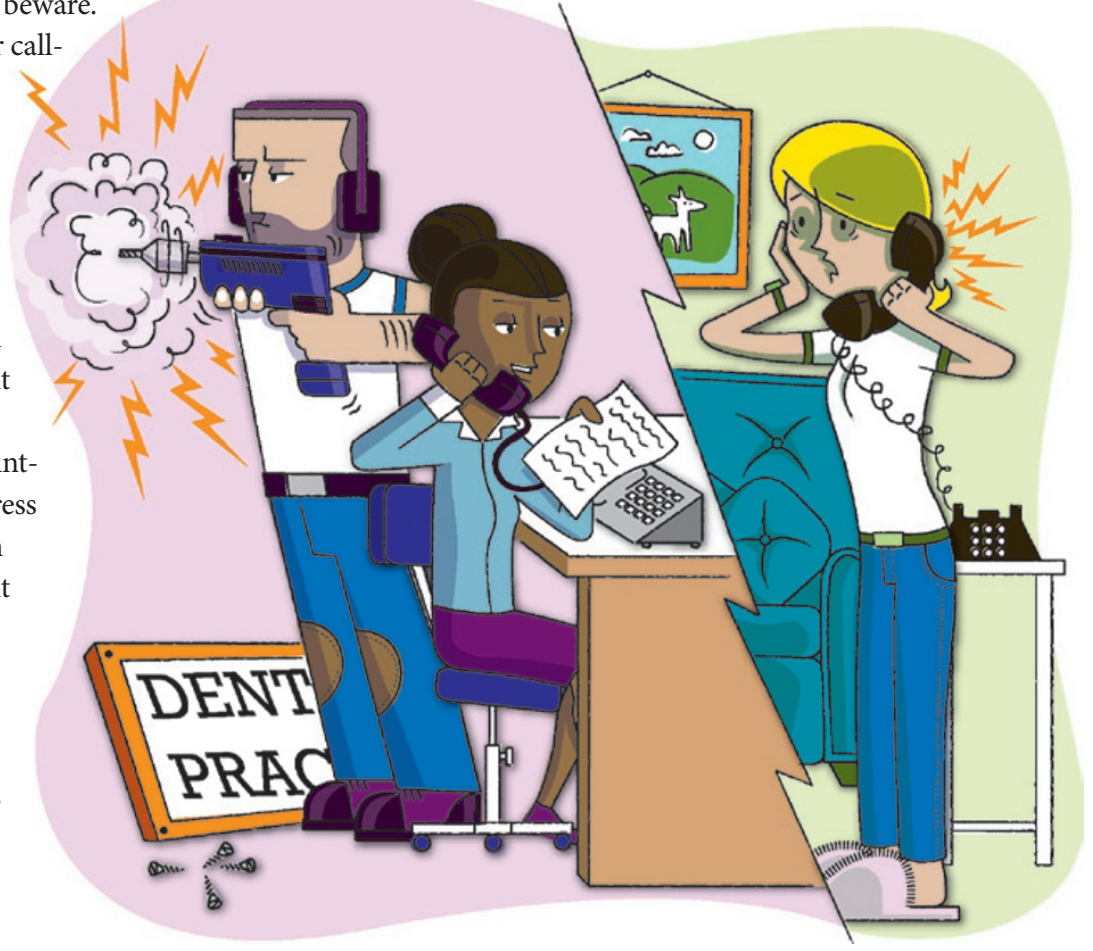

